\title{
Visões "rivais" sobre mudança estrutural e proteção social
}

Flávio da Cunba Rezende

Professor do Programa de Pós-Graduação em Ciência Política da UFPE

\section{Palauras-chave}

gastos sociais, políticas sociais,

teorias sobre expansão

dos gastos sociais.

Classificação JEL H50, H55,

\section{Key words}

social expenditure, social policies,

theories regarding expansion

of social expenditures.

JEL Classification H50, H55,

\section{Resumo}

O artigo analisa a relação entre mudança estrutural e intervenção social do Estado. Ele analisa comparativamente os mecanismos centrais de três teorias contemporâneas que tentam explicar as principais razões pelas quais os gastos sociais se expandem nas sociedades contemporâneas.

\section{Abstract}

This paper discusses the relationship between structural change and social policies. It provides a comparative analysis of the basic mechanisms of three major lines of theoretical reasoning that seeks to explain the main reasons by which governments continue to expand their social expenditures in contemporary societies. 


\section{1_ Introdução}

A expansão dos gastos sociais é um dos fenômenos constitutivos das sociedades modernas. A despeito do argumento de que o welfare state estaria em erosão, e de um movimento em direção às sociedades de mercado em contextos de globalização e interdependência crescente, evidências comparativas mostram que os Estados continuam a exibir fortes padrões de intervenção nas políticas sociais. Os gastos sociais representam grande porção dos gastos governamentais ${ }^{1}$, e, contrariamente aos discursos sobre uma possível "retirada do Estado da área social", observa-se expressiva expansão das políticas sociais. No Brasil, apesar de uma suposta "onda" de reformas estruturais voltadas para a construção de uma sociedade de mercado, o Estado continua a investir pesadamente na área social, e, comparativamente aos anos 90, os gastos públicos na área social são consideravelmente elevados e continuadamente crescentes.

As sociedades contemporâneas estariam, portanto, vivendo um grande dilema: ao mesmo tempo em que legitima e amplia o discurso de "redução e controle da expansão" dos gastos públicos, haveria uma ampla gama de fatores que estariam levando o Estado a continuar produzindo elevados níveis de intervenção nas políticas sociais. Até que ponto seria razoável argumentar que processos de transformação estrutural, tais como a globalização, privatizações, liberalizações e desregulamentação econômica, estariam redefinindo um novo papel para o Estado na questão relativa à proteção social?

A resposta a esse problema é tratada neste artigo com base na análise de três teorias rivais (e, em alguma medida complementares) que tentam dar conta da complexa relação entre transformações estruturais e intervenção social do Estado nas condições das sociedades contemporâneas. $\mathrm{O}$ artigo se desenvolve com o propó sito de tentar compreender quais os mecanismos básicos através dos quais essas teorias fundamentam a intervenção dos Estados na proteção social.

As teorias consideradas neste estudo relacionam a intervenção social a fatores estruturais tais como desindustrializa ção, globalização e envelhecimento populacional. Essas mudanças estruturais estariam demandando maior intervenção social, rompendo com a tradicional idéia de que as sociedades de mercado exigem a "diminuição" relativa das intervenções nas políticas sociais. A análise dos mecanismos centrais dessas teorias permitirá compreender se existem pontos de convergência i . . . . . . . . . evidências comparativa produzidas por Tanzi e Schuknecht (2000), se, ao final do século XIX os gastos públicos representavam $10,8 \%$ do Produto Interno Bruto nas sociedades de maior renda, ao final do século $\mathrm{XX}$, quase metade da riqueza produzida foi destinada para os gastos com programas e políticas públicas.

2 Os gastos sociais

brasileiros se expandiram consideravelmente no período

1995-2006. Considerando

séries históricas a preços

constantes de 2006

(deflacionadas pelo

IPCA-IBGE), evidências

comparativas revelam

que os gastos com Previdência

Social passaram de R $\$ 104,2$

bilhões para $\mathrm{R} \$ 290,7$ bilhões;

os gastos com saúde passaram

de $\mathrm{R} \$ 34,4$ bilhões para

R\$ 79,9 bilhões; os gastos

com educação saltaram

de $\mathrm{R} \$ 20$,2 bilhões para

R \$ 41,0 bilhões; e, os gastos

com os programas na área de

proteção ao trabalho sofreram

uma variação de $R$ \$15,1

bilhões para $\mathrm{R} \$ 58,6$ bilhões

no mesmo período. 
entre tais teorias que serão fundamentais para que se possa argumentar sobre uma rationale em nível mais profundo sobre a intervenção do governo na área social.

O artigo está organizado da seguinte forma. $\mathrm{Na}$ primeira parte apresentamos as explicações estruturais em sua forma mais tradicional e geral, e, em seguida, particularizaremos para o caso das teorias que se voltam para a expansão da proteção social, focalizando em três "modalidades ou famílias" de argumentação: desindustrialização e a expansão das políticas sociais; a conexão entre globalização e proteção social; e, em seguida, o peso das explicações que focalizam na transformação da composição populacional (envelhecimento) das sociedades modernas como fator decisivo na manutenção dos padrões de gastos públicos.

\section{A proteção social nas sociedades contemporâneas}

Com base em Polanyi (1944) em seu inovador estudo do colapso da sociedade liberal do século XIX, considera-se que a proteção social do Estado é um dos elementos de fundamental importância para a construção da ordem social no século XX. De forma radicalmente diferente que em períodos históricos anteriores, a intervenção do Estado nas áreas de proteção social representou fato novo na dinâmica social moderna, e, de forma inédita, o Estado ampliou seus sistemas de produção de políticas nas áreas de bem-estar social e ainda em uma série de serviços sociais considerados essenciais para a vida em sociedade. A intervenção social do Estado passa a se transformar consideravelmente a partir dos anos $30 \mathrm{e}$ atinge o seu auge em termos de expansão na chamada "era de ouro do capitalismo". Tal padrão entra em crise a partir dos anos 80, graças a uma conjunção de fatores sociais, econômicos e políticos, que articulam uma nova experiência histórica para as sociedades modernas. Enquanto em 1930, para um conjunto dos 17 países mais ricos e desenvolvidos, os gastos públicos com aposentadorias e pensões eram de apenas $1,2 \%$ do PIB (em valor médio), em 1993, essa média atingiu aproximadamente $10 \%$ da riqueza nacional, sugerindo um esforço intervencionista na área da proteção social (Tanzi e Schuknecht, 2000).

Para as sociedades contemporâneas, como argumenta Offe (1999), os modelos tradicionais de provisão de recursos centrados no Estado ou nos mercados do século XX estariam cedendo espaço para alternativas mais híbridas desde a crise 
multifacetada que se abateu sobre as bases institucionais das sociedades ocidentais em seu processo para uma ordem progressivamente mais pós-moderna e democrática, em contexto permanente de expansão de demandas e crise fiscal. Uma das principais características centrais dos novos modelos é a tentativa de introduzir desenhos institucionais capazes de permitir múltiplas combinações entre a sociedade civil, o Estado e o mercado. Em conseqüência, os modelos tradicionais da interferência do Estado na área social passaram a ser vigorosamente repensados. O novo papel do Estado na esfera da proteção social aparece como marca registrada dessa nova ordem e tem sido alvo de profundas metamorfoses nas diversas sociedades contemporâneas. Em sua reflexão sobre os elementos que devem compor os modelos institucionais híbridos para a produção da ordem social, Offe (1999) argumenta claramente que precisamos encontrar alternativas que integrem as diferentes racionalidades e potencial dos modelos tradicionais.

Os estudos comparativos organizados por Pierson (2001) apontam no sentido de mostrar uma reconfiguração entre uma "nova lógica da produção dos welfare states" em um contexto de escassez de recursos e de crise fiscal das sociedades contemporâneas. O debate teórico contempo- râneo sobre os limites da intervenção social do Estado oscila num espectro altamente polarizado em que duas posições são conflitantes. A primeira delas argumenta que o aprofundamento dos processos de globalização dos mercados produziria maiores demandas por intervenção social. A outra versão é aquela que identifica a expansão dos mercados como diretamente ligada à difusão de idéias e agendas de corte neoliberal cujo interesse central é reduzir a esfera social dentro de paradigmas minimalistas da ação do Estado. Rezende (1996 e 2002), em na sua hipótese dos "Leviatãs estão fora do Lugar", sugere que a experiência comparada apresenta uma curiosa resposta às metamorfoses na intervenção do Estado na área social:

As nações de maior renda e com maior gran de desenvolvimento apresentam perfis conservadores em termos da magnitude e composição do gasto social, enquanto que são os paises de menor renda e desenvolvimento que se aproximam dos padrões do Estado minimo.

Em termos das principais argumentações teóricas sobre a relação entre os condicionantes estruturais e a intervenção social dos Estados, as diversas teorias produzidas pela economia política ao longo dos anos 90 exibem alto grau de rivalidade em termos das suas proposições, conforme 
apresentaremos em seguida. Todavia, elas se voltam para explicar em que medida e por meio de que mecanismos tais condicionantes estruturais produziriam impactos sobre a magnitude e a composição dos gastos sociais. Condicionantes estruturais tais como a globalização dos mercados, a democratização da política, a exposição aos riscos crescentes da competição econômica e financeira bem como as mudanças tecnológicas no mundo do trabalho, ou mesmo o envelhecimento populacional assumem primazia causal para explicar a (não) emergência dos novos padrões de gastos na proteção social.

Baseados em estudos comparativos que combinam revisões teóricas e testes empíricos comparados, apresentaremos três "estudos de caso" para ilustrar modelos teóricos típicos que compõem o debate contemporâneo sobre o problema dos gastos sociais. O primeiro modelo teórico propõe que os processos de abertura das economias aos mercados representam os principais mecanismos para explicar o comportamento dos Estados diante das demandas por intervenção social. A segunda teoria desenvolve o argumento de que processos de desindustrialização característicos das sociedades pós-industriais e globalizadas assumem centralidade na explicação. Em ambas as versões reside uma argumentação comum de que a expansão dos riscos gerados pela competição econômica (seja esta gerada por mudança tecnológica ou por abertura dos mercados domésticos) produz demandas por proteção social. Esses processos aparecem como essenciais para compreender os nexos que interligam a ação econômica e as políticas de intervenção social do Estado em estudos de caso ou comparativos. A terceira análise empreendida trata da versão estrutural que coloca a composição populacional como fator decisivo na transformação dos padrões dos gastos sociais na sociedade contemporânea.

\section{Desindustrialização, riscos e expansão das políticas sociais}

Iversen (2000) e Iversen e Cusack (2000) são estudos que teorizam sobre a conexão entre desindustrialização, expansão dos riscos e intervenção social. O nexo causal proposto pelos autores é o de que processos de redução simultânea do emprego nos setores industrial e agrícola nas sociedades pós-industriais e desenvolvidas assumem primazia na explicação das mudanças no papel e magnitude da intervenção social. A lógica apresentada pelos autores é a de que a expansão dos gastos sociais deriva dos riscos pro- 
duzidos pela desindustrialização, e não pela abertura das economias. O mecanis mo básico é o de que a redução do emprego nos setores industrial e agrícola eleva as demandas sociais por programas sociais compensatórios, especialmente em sociedades democráticas e com forte organização político-partidária. A política desempenha papel decisivo nesse processo, e governos de maior inclinação para agendas redistributivas, tais como os governos de orientação ideológica de esquerda, tenderiam a expandir os gastos sociais, para o caso das sociedades com Estados de Bem-Estar altamente institucionalizados. A análise sugere, portanto, que os processos de globalização não se constituiriam uma ameaça para a presença dos Estados na área social.

A ação política desempenha papel decisivo na explicação da dinâmica de produção dos gastos sociais diante da expansão dos riscos. Agentes sociais interagem com as instituições políticas para produzir um conjunto de decisões governamentais relativos à emergência, manutenção e introdução de outros programas na área social. A organização de interesses em torno das disputas pela redistribuição de recursos pela via da política revela os modos específicos pelos quais o Estado tenta atender à compatibilização das demandas coletivas com a dispo- nibilidade de recursos orçamentários. As democracias são ambientes marcados por profundas disputas por inclusão e redistribuição entre grupos sociais, fato que move os governos para expandir sua oferta de políticas sociais, seja para reduzir os efeitos perversos da desindustrialização, seja para garantir níveis adequados de investimento em áreas como educação, saúde, e mesmo atenção aos grupos vulneráveis, tais como os pobres e os idosos. A ideologia desempenha papel importante no modo em que as políticas lidam com o conflito distributivo: de forma geral, governos de direita tendem, na experiência das sociedades desenvolvidas, a expandir a proteção social pela via das políticas de transferências de renda para grupos vulneráveis. Por outro lado, os governos de esquerda buscam mecanismos de melhorias salariais e expansão da oferta benefícios sociais, tais como créditos e subsídios específicos.

Articulando padrões híbridos de intervenção social, as políticas sociais nos países de maior renda e grau de desenvolvimento refletem as estratégias de resposta aos processos de transformação da estrutura do emprego articulando o Estado, o mercado e a sociedade civil. A primeira estratégia focaliza na desregulamentação econômica e dos mercados de trabalho, visando expandir a oferta de emprego no se- 
3 Superando as explicações tradicionais formuladas pela explicação proposta por Cameron (1978), a qual afirmava haver relação entre a expansão dos gastos públicos e a questão da abertura da economias, sendo aquela atribuída a forte sindicalização e organização dos interesses em torno de barganhas coletivas por proteção social via ação coletiva, ao menos para as sociedades de maior renda e para o período compreendido entre 1960 e 1975. O Estado desempenharia o papel de promotor da redução do impacto social dos mercados. tor privado. A segunda opção tem sido a de regulação extensiva dos serviços públicos e dos salários e combinação à expansão do emprego no setor público. O aumento dos sistemas e mecanismos tradicionais de proteção social se constitui na terceira opção. Iversen e Cusack (2000) argumentam que a preferência por uma dessas estratégias de políticas (ou combinação delas) está fortemente ligada ao modo pelo qual as instituições do mercado de trabalho e os partidos políticos operam em cada sociedade. A ação política aparece como decisiva. $\mathrm{O}$ papel do Estado como instituição dotada de autoridade e competência para organizar o processo de transferência das habilidades e competências (transferability of skills) entre grupos sociais e entre gerações é decisivo para reduzir os efeitos negativos da reestruturação econômica das sociedades. Apesar da primazia causal ao fator desindustrialização e aos riscos, variáveis políticas e institucionais desempenham papel ativo na explicação proposta pelos autores que trabalham nessa linha. A ação política exerce papel central na organização de interesses coletivos na busca por proteção social junto ao Estado. Em condições que combinam a coexistência de organizações de representação de interesses fortes e centralmente organizadas e os governos majoritariamente compostos por partidos que privilegiam agendas redistributivas, as agendas de intervenção social tendem a se expandir, ou, em contextos de forte pressão fiscal, a ser conservada. Isso explica em grande parte por que nas sociedades européias com forte tradição de welfare state, as transformações tecnológicas e a reestruturação produtiva tendem a ser acompanhadas por uma expansão dos gastos públicos.

\section{Abertura econômica,}

\section{globalização e proteção social}

A tese rival é a de que os processos de abertura e liberalização das economias são fatores decisivos para explicar a intervenção social dos governos diante da globalização. Rodrik (1996) formula uma importante e surpreendente linha de argumentação sobre o papel do Estado no contexto de uma sociedade que está exposta aos riscos da competição internacional. ${ }^{3}$ A abertura econômica e a expansão do Estado guardavam relação positiva e significativa. A idéia subjacente à explicação "econômica" proposta pelo autor é a de que o governo atua como um importante mecanismo redutor dos riscos produzidos pela interdependência econômica e expansão das transações comerciais entre nações. Nas sociedades expostas à competição e aos riscos pro- 
duzidos pela globalização, existe um trade-off entre a expansão do papel social do Estado e a institucionalização de políticas públicas liberalizantes.

A tese de que a globalização produziria uma expansão dos gastos públicos é sustentada por Alesina e Wacziarg (1997). Eles tentam explicar por que os processos de globalização dos mercados, ao expandir a interdependência entre as economias e a demanda por "abertura" comercial, alteram as formas tradicionais de intervenção do Estado. Eles sugerem que esses processos preservam relação direta com a escala da economia que se considere. Para economias de menores dimensões e mais expostas à abertura comercial, por um lado, expandem-se as demandas pela regulação e intervenção do Estado. A expansão do Estado é considerada como fundamental no sentido de produzir instituições que reduzam as incertezas geradas pela exposição aos mercados competitivos e compensar as tradicionais falhas de mercado. Os gastos sociais são expandidos para proteger as economias das flutuações econômicas dos mercados. Os países de maior dimensão geográfica podem lançar mão dos mercados internos reduzindo a demanda por abertura comercial, e conseqüentemente, por gastos públicos em políticas sociais.
Boix e Asdera (2000) partem da premissa de que grande parte da literatura teórica que tenta dar conta da conexão entre abertura econômica e políticas públicas desconsidera as variáveis relativas à ação política. Eles argumentam que a ação política é decisiva para explicar padrões de conflito distributivo pela redistribuição dos gastos sociais pelo Estado em resposta aos processos de integração econômica com os mercados globais. $\mathrm{O}$ modelo proposto tenta descrever o comportamento de um "formulador de políticas públicas" que tenta manter-se no poder maximizando as funções de bem-estar do eleitor mediano. Os atores decisivos enfrentam decisões sobre trade-offs políticos e econômicos que estruturam a escolha de políticas fiscais e de liberalização econômica. As elites domésticas disporiam de três estratégias de integração econômica diante dos conflitos por redistribuição produzidos pelo eleitor mediano no processo político.

A primeira opção seria a de promover o insulamento das elites estratégicas buscando evitar que as mudanças nos preços relativos nos sistemas econômicos internacionais tendam a produzir maiores demandas por proteção social. A construção de agendas mais liberais de desenvolvimento tendo a expansão do setor público como recurso crítico para proteger setores 
econômicos específicos se apresenta como a segunda via de ação. Por fim, eles consideram que as elites estratégicas podem recorrer aos regimes autoritários para evitar os riscos de elevada carga tributária que deriva da combinação entre abertura econômica e expansão de sistemas compensatórios, externalizando os custos da liberalização para outros grupos sociais excluídos da competição internacional. A via autoritária permite que os custos do conflito e da competição sejam reduzidos. Os caminhos possíveis sugeridos pelos autores evidenciam que a relação entre exposição à competição internacional é essencialmente mediada pela conexão entre agência, instituições e decisões políticas em contextos específicos de tempo e espaço. Contrariamente ao senso comum, a globalização não necessariamente produz mais ou menos intervenção social, mas sim ela opera como uma matriz de condicionantes que permite conectar os interesses estratégicos das elites decisórias em torno de opções de expandir ou não os recursos na direção de políticas mais redistributivas ou mais conservadoras para atender às preferências do eleitor mediano.

A relação entre globalização, democracia e padrões de gastos sociais para 19 países latino-americanos no período 19801997 é analisada no modelo comparativo por Avelino, Brown e Hunter (2000). O modelo proposto tenta testar a validade de duas consagradas hipóteses sobre as relações entre política social e globalização. A primeira delas, conhecida como a hipótese da eficiência, considera que os governos respondem aos processos de globalização com redução dos gastos em programas sociais, enquanto que a segunda considera que há uma ação de expandir o gasto social para compensar as perdas sociais produzidas pela globalização.

$\mathrm{Na}$ primeira hipótese, o mecanismo causal é o de que os governos tendem a reduzir os impostos e os gastos sociais que criam incentivos negativos para o crescimento econômico e a competitividade internacional. A principal relação esperada seria a de que os processos de abertura econômica produziriam restrições para as políticas sociais. Por outro lado, embora reconheça tais restrições, as teorias que argumentam na direção da hipótese da ação compensatória do Estado, como já discutido em seção anterior, enfatizam as relações entre as ofertas de políticas públicas pelos políticos e pelos burocratas e a crescente demanda dos grupos por proteção social. Os políticos e os burocratas utilizam estrategicamente as políticas sociais como mecanismos de proteção aos riscos produzidos pelos processos de abertura econômica e 
financeira. Os gastos sociais em determinados programas sociais, especialmente aqueles de natureza compensatória, tenderiam a se expandir com a globalização.

Contrariamente aos resultados encontrados pelo estudo de Kaufman e Segura (2001) para o caso latino-americano, os resultados encontrados pelos autores sugere haver uma lógica dual de articulação entre globalização, democracia e gastos públicos, a qual varia em função do tipo de programa social considerado. Esse importante resultado é derivado de que a abertura comercial esteve negativamente correlacionada aos gastos sociais, ao passo que a abertura financeira produziu resultado polar oposto na experiência da amostra considerada. A desagregação dos gastos sociais foi escolhida como opção para compreender os diferentes impactos da democracia sobre os gastos públicos em educação, saúde e previdência social. Importante resultado nessa direção mostra que a democratização na América Latina teve impacto positivo sobre os gastos em educação. A abertura comercial da economia está negativamente correlacionada com os gastos sociais, enquanto a abertura financeira esteve positivamente com os gastos em educação e saúde. As recomendações deste estudo incluem o refinamento dos modelos que permitam teorizar sobre a conexão entre globa- lização e instituições políticas domésticas valendo-se de metodologias que permitam trabalhar as múltiplas tipologias das políticas sociais de forma desagregada.

Embora a variável política desempenhe papel importante na explicação, ao concentrar ênfase na democracia como principal componente político no modelo proposto, esse deixa de considerar o papel do federalismo e da descentralização política, fiscal e administrativa que reconhecidamente desempenha papel decisivo sobre os padrões de gastos públicos nas democracias da América Latina. Variáveis tais como desenho institucional, relação Executivo-Legislativo, natureza dos processos decisórios nas diferentes políticas sociais, capacidade gerencial (state capacity), profissionalização, grau de insulamento decisório, participação e representação, poderiam ser úteis para compreender mais de perto a conexão entre globalização e democracia no contexto latino-americano. Embora a inclusão dessas variáveis seja necessária para um refinamento dos modelos, as teorias utilizadas partem do pressuposto de que as variáveis exógenas, no caso, a globalização, que impacta sobre os gastos sociais mediadas pela democracia, e não aqueles que levariam em conta que os fatores endógenos por exemplo, o desenho institucional ou processo decisório, ou mesmo na opção 
estratégica dos atores (representadas pela posição do eleitor mediano ou decisivo) no processo político que produziria determinados padrões de intervenção pública na área social. A ênfase nos processos de abertura comercial tende a ultrapassar os microfundamentos da explicação, necessárias para compreender mais de perto a conexão entre política, instituições e gastos sociais. Teorias que focalizem em padrões mais desagregados de políticas sociais poderiam incorporar variáveis que capturem os mecanismos que estruturam as conexões causais que explicariam com maior robustez a conexão entre democracia e intervenção social do Estado.

\section{Composição populacional \\ e expansão dos programas \\ de proteção social}

Outra tese importante no debate relaciona a expansão dos gastos sociais à mudança da estrutura populacional das sociedades. Nessa interpretação, muito freqüente nos modelos e estudos empíricos comparados, a variável taxa de dependência (dependency ratio) tenta compreender o decisivo impacto da participação de grupos sociais de atores com idade superior a 65 anos ou mesmo os menores de 15 anos sobre o comportamento expansivo dos gastos públicos.
Uma tese central desse debate é a de que o aumento da longevidade nas sociedades tende a produzir significativa expansão dos gastos sociais. Os gastos previdenciários tenderiam a se expandir consideravelmente em sociedades em que o percentual da população superior a 65 anos atinge níveis razoáveis. As transformações no perfil populacional visa a produzir um efeito surpreendente sobre a conexão entre política e questão do conflito distributivo. As instituições políticas passam a ser mecanismos mediadores para as formas que vão se delinear as alternativas de superação do conhecido problema da redistribuição entre gerações. O conflito político que se estrutura a partir da mudança populacional é decisivo para explicar a expansão dos programas de proteção social.

Em linhas gerais, esse conflito político se estrutura em torno das preferências de dois grupos: os beneficiários das políticas de previdência e seguridade social que defendem a manutenção do status quo no tempo $t$, e os grupos que não são beneficiários e que atualmente contribuem para a oferta de tais serviços. Diferentes regimes políticos e arranjos institucionais acomodarão as formas de resolução desse conflito. $\mathrm{O}$ aumento do peso das preferências dos atores que se beneficiam hoje com a importante questão da proteção social para 
esses grupos tende a pressionar a política por agendas que insiram maior atenção com programas sociais voltados para os eleitores com idade superior aos 65 anos em detrimento de outros grupos sociais Esse problema é típico de sociedades desenvolvidas, mas também afeta sociedades como a brasileira na qual considerável parte do gasto social federal é de natureza previdenciária. A participação eleitoral desse grupo social aparece como importantíssimo elemento para explicar as decisões coletivas em torno dos padrões de gastos sociais. O peso eleitoral desse grupo na competição política inclina-se a alterar a posição eleitor mediano em favor da maior intervenção do Estado, o que lhes confere grande latitude para atrair atores políticos estrategicamente interessados em expandir os gastos sociais na direção desses grupos em troca de apoio eleitoral.

A expansão dos programas previdenciários é usualmente explicada por teorias que interpretam as decisões de gastos como um conflito intertemporal entre grupos. A preferência dos eleitores por programas previdenciários dependeria fundamentalmente de sua idade e renda. A teoria supõe que a ação de coalizões formada por atores políticos que representam eleitores pobres e de dependentes da redistribuição via previdência, seria aquela que teria maior interesse em apoiar plataformas políticas voltadas para manter ou expandir os benefícios sociais. Essa coalizão tenderia, em tese, a pressionar por uma expansão indevi$\mathrm{d}$, uma vez que seus principais opositores (os ricos e não beneficiários) não poderiam participar das escolhas sobre tais políticas. O processo político traduziria um generalizado movimento de transferência de recursos do eleitor mediano (median voter) para os beneficiários líquidos do welfare state. Por sua vez, os governos precisam atuar estrategicamente para definir a carga tributária necessária para financiar a expansão das transferências sociais para tais grupos, o que depende da posição do eleitor mediano. Caso esse se posicione na situação de beneficiário ou de contribuinte de um sistema previdenciário, a carga tributária vai variar consideravelmente. No primeiro caso, os beneficiários tentarão apoiar a expansão do esforço fiscal (especialmente em sistemas previdenciários do tipo pay-asyou-go, em que os contribuintes pagam e os beneficiários recebem suas aposentadorias) a expensas dos contribuintes, e, no outro caso, os beneficiários tentariam se valer de estratégias políticas de sobrevivência no processo político bloqueando as tentativas de reformas da previdência. Muito conhecido nesta literatura é a relação positiva entre a taxa de dependência por proteção 
social e a montagem de coalizões políticas que tentam impor agendas de políticas públicas que promovem a expansão da carga tributária.

A relação entre política e gastos sociais se evidencia na interpretação oferecida pelo estudo comparativo de Snyder e Yackovlev (2000) para o caso dos EUA e de grupo de países latino-americanos. Os autores sugerem que a estabilidade (ou caráter não-cíclico) dos programas sociais depende consideravelmente do tipo de programa que se considere. Pelo fato de materializarem diferentes formas de agregar interesses de grupos em torno de redistribuição sob diferentes formas, as políticas sociais enfrentam diferentes graus de "riscos políticos" e "vulnerabilidade" política. Para o caso americano, eles sugerem não ter havido diferenciações de vulnerabilidade quando se consideram aspectos como focalização, universalização ou distribuição geográfica dos benefícios produzidos pelas políticas. Todavia, aquelas políticas focalizadas nos grupos pobres tendem a exibir vulnerabilidade quando ocorrem mudanças no controle político no Congresso, especialmente quando os republicanos assumem o poder. Para o caso latino-americano, por contraste, as políticas de proteção social são altamente vulneráveis aos ciclos econômicos e políticos. A instabilidade dos gastos em educação e saúde para os casos analisados sugere haver uma influência da variável política sobre a mudança nas políticas públicas.

Os regimes políticos desempenham papel decisivo para explicar o comportamento cíclico das decisões coletivas sobre o gasto social. Todavia, eles sugerem que o refinamento sobre a explicação dos diferentes padrões de relações entre política e gastos públicos podem ser mais bem compreendidas se a categoria analítica "gasto social" for desagregada ou decomposta em tipos distintos de programas e projetos. Um resultado desafiador da análise comparativa é a reduzida influência da variável ideologia política sobre a mudança dos padrões de políticas públicas para os casos do Brasil e da Colômbia. Mas, conforme sugerem os autores, as variações no controle político nos países estudados teriam impacto relevante. Mudanças no controle político produziriam significativas mudanças no gasto social para os casos latino-americanos. Decorrente do crônico problema de organização das demandas e formação de clientelas no padrão de relacionamento entre Estado e sociedade na produção de políticas públicas, esse processo se dá de forma errática e com grande instabilidade nos padrões de atendimento às demandas sociais dos grupos. No caso americano, as cli- 
entelas desempenham papel decisivo na proteção dos programas sociais evitando flutuações na distribuição geográfica e intragrupos na sociedade. As políticas importam para explicar a política e os padrões de gastos como explicam os tradicionais estudos na área de política pública.

\section{6_Considerações finais}

Este artigo apresenta teses aparentemente rivais que estruturam os debates contemporâneos em torno da questão da expansão dos gastos públicos num contexto de crescente globalização, democratização e de intensificação das lógicas de mercado. A análise comparada dos mecanismos basilares dessas teorias revela no entanto, que existem zonas de convergência entre tais argumentos. Eles basicamente são convergentes ao considerar que o papel do Estado na área social está diretamente associado ao conflito político gerado pelo risco das mudanças estruturais que são típicas dos modelos mais competitivos de organização política e econômica. A proteção social encontra fundamentação teórica na idéia de redução dos riscos e incertezas que tendem a se mostrar no contexto de expansão dos mercados globais e das democracias políticas. Sociedades continuam a demandar intervenção social não apenas para corrigir as falhas de mercado, mas para tornar as instituições políticas e econômicas mais confiáveis e dotadas de poder de competitividade nos mercados. A necessidade de redução dos riscos políticos visa a ampliar as chances de que os gastos sociais sejam expandidos. A aversão ao risco (econômico e político) passa a ser o elemento decisivo para compreender por que as sociedades utilizam ou não modelos mais intervencionistas de proteção social, o que não depende apenas de questões ideológicas ou partidárias, mas, fundamentalmente, da necessidade de estabilidade das políticas econômicas num contexto de crescente competição econômica. 
Referências bibliográficas

ALESINA, Alberto;

WACZIARG, Romain. Openness,

country size, and the governmen

Cambridge. NBER Working

Papers. Cambridge, 1997.

(Working Paper, 6024.)

AVELINO, George; BROWN, David; HUNTER, Wendy.

Globalization, democracy, and social spending in Latin America, 1980-1997. Paper Prepared for the APS A Annual Meeting, 2000.

BOIX, Charles; ASDERA,

Alicia. Trade, democracy, and

the size of the public sector:

The Political Underpinning of

Openness, 2000. Mimeo.

IVERSEN, Torben. The dynamics of Welfare State Expansion: trade openness, deindustrialization,

and partisan politics. Forthcoming

in Paul Pierson (Ed.). The

New Politics of Welfare State.

Oxford. Oxford University

Press, 2000. Mimeo.

IVERSEN, Torben; CUSACK.

The causes of Welfare State

Expansion: Deindustrialization

and globalization? World Politics,

v. 52, p. 313-49, April 2000.
KAUFMAN, Robert R.;

SEGURA-UBIERGO, Alex.

Globalização, política interna

gasto social na América Latina:

uma análise de corte transversa

com série temporal, 1973-1997.

Dados. Revista de Ciências Sociais,

Rio de Janeiro, v. 44, n. 3

p. 435-479, 2001.

OFFE, Claus. A atual transição d

história e algumas opções básicas

para as instituições da sociedade.

In: BRESSER PEREIRA, Luiz

Carlos; SOLA, Lourdes;

WILHEIM Jorge (Orgs.). Sociedade

Estado em Transformacão. São

Paulo. Ed. UNESP. p. 119-146, 1999. (Cap. 4).

PIERSON, Paul. The new politic the Welfare State. New York.

Oxford University Press, 2001.

POLANYI, Karl. The Great

Transformation: the political and

economic origins of our time.

Boston. Beacon Press, 1944.

REZENDE, Flávio da Cunha.

S Leviatãs estão fora

do Lugar. Dados, v. 39, n. 2.

p. 196-211, 1996.
REZENDE, Flávio da Cunha.

Gastos públicos e mudanças

recentes no papel do Estado

Nacional: uma análise comparada

entre países desenvolvidos e

Estudos Cebrap, n. 62, p. 123-140,

mar. 2002.

RODRIK, Dani. Why do more

open countries have bigge

governments? NBER

Working Papers. April, 1996

(Working Paper, 5537).

SNYDER, James M.

YACKOVLEV, Irene. Political

and economic determinants

of government spending on

social protection programs.

MIT Working Papers. Abril,

2000. Mimeo.

TANZI, Vito;

SCHUNKNECHT, Ludger.

Public spending in the 20th Century:

a global perspective. New York.

Cambridge University

Press, 2000.

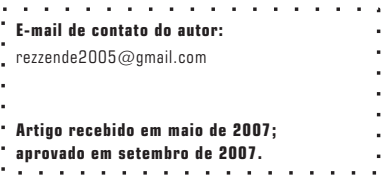

aprovado em setembro de 2007 